\title{
QUANTITATIVE DETERMINATION OF RESIDUAL SOLVENTS IN PALONOSETRON API BY HS-GC METHOD
}

\author{
SUNNY GRACE GODE ${ }^{1}$, VIJAYA LAKSHMI GOLLAPALLI ${ }^{2 *}$ \\ ${ }^{1}$ Department of Pharmacy, University College of Technology, Osmania University, Hyderabad, Telangana, India. ${ }^{2}$ Department of Chemistry, \\ Osmania University College for Women, Koti, Hyderabad, Telangana, India. Email: sunnygrace2000@gmail.com
}

Received: 22 November 2021, Revised and Accepted: 10 January 2022

\section{ABSTRACT}

Objectives: Palonosetron is an antidote to $5-\mathrm{HT}_{3}$ in the prevention and treatment of chemotherapy-induced nausea and vomiting (CINV). The presence of residual solvents in pharmaceutical drug substances or products, as well as excipients, can have a detrimental effect on the product's quality and stability. These substances must be evaluated for safety and efficacy. The primary purpose of this work is to establish a method for validating and quantifying residual solvents in palonosetron API using Head Space Gas Chromatography (HS-GC).

Methods: In the proposed HS-GC technique for the quantifying residual solvents - ethanol, acetone, methanol, acetonitrile, and isopropyl alcohol (IPA) in Palonosetron API, the headspace equilibrium was achieved at $100^{\circ} \mathrm{C}$ and analyzed by DB-624 column ( $\left.30 \mathrm{~m} \times 0.24 \mathrm{~mm}, 1.8 \mu \mathrm{m}\right)$ with injector and detector temperature set at $200^{\circ} \mathrm{C}$ and $230^{\circ} \mathrm{C}$ respectively. The dissolving solvent was dimethyl sulfoxide (DMSO). After the initial holding time of $5 \mathrm{mins}$, the temperature was increased to $120^{\circ} \mathrm{C}$ from $40^{\circ} \mathrm{C}$ in $20 \mathrm{mins}$ at a rate of $10^{\circ} \mathrm{C} / \mathrm{min}$ using a flow rate of $10 \mathrm{ml} / \mathrm{min}$ and a split ratio of $1: 25 \mathrm{with}$ nitrogen as carrier gas. The approach created has been validated and quantified as per International Conference on Harmonization's (ICH) guidelines.

Results: All the results obtained were within the ICH specified limits. The validation results for repeatability studies (\%RSD values) were found to be $<10$; recovery studies values were in the range of $90-110 \%$ and for the selected linearity range $25-150 \mu \mathrm{g} / \mathrm{ml}$ the correlation coefficients $\left(\gamma^{2}\right)$ for all the solvents were observed to be $>0.99$.

Conclusion: A sensitive, simple, precise, and economic HS-GC method with Flame Ionization Detector (FID) was developed and validated to quantitatively determine the residual solvents in Palonosetron API.

Keywords: Palonosetron, Residual solvents, Headspace gas chromatography, International conference on harmonization.

(C) 2022 The Authors. Published by Innovare Academic Sciences Pvt Ltd. This is an open access article under the CC BY license (http://creativecommons.org/ licenses/by/4.0/) DOI: http://dx.doi.org/10.22159/ajpcr.2022v15i2.43669. Journal homepage: https://innovareacademics.in/journals/index.php/ajpcr

\section{INTRODUCTION}

Palonosetron, chemically known as (3aS)-2-[(3S)-Quinuclidin-3-yl]2,3,3a,4,5,6-hexahydro- $1 \mathrm{H}$-benzo[de]-isoquinolin-1-one; is 5 - $\mathrm{HT}_{3}$ receptor antagonist suggested for the treatment of nausea and vomiting associated with moderately-emetogenic cancer chemotherapy and post-operative nausea and vomiting. The anti-emetic effect is achieved by inhibiting $5 \mathrm{HT}_{3}$ receptors in both the central nervous system (medullary chemoreceptor zone) and peripheral nervous system (gastrointestinal tract) [1]. The FDA approved this medication in 2014 for use in combination with netupitant to treat CINV [2].

Residual solvents (RS) are frequently used in the manufacture of pharmacological compounds, excipients, and finished pharmaceutical products. Their presence is undesirable in the final product as it may affect the quality and stability of the drug which can be unpleasant for the patients. Even after applying various techniques to remove them, some solvents are still retained in small quantities. The need to test and control RS in pharmaceutical products was recognized in the late '70s [3]. Pharmaceutical products must be tested for 'RS when production or purification of processes known to produce or purify solvents' according to ICH harmonized guidelines set up by the European Union, Japan, and the United States for the registration of pharmaceutical products [4]. These guidelines specify the analytical procedures used to identify and quantify residual solvents, as well as the permitted acceptable concentration limits. Table 1 summarizes the $\mathrm{RS}$ concentration limitations for palonosetron.

Gas chromatography (GC) is a choice of analytical method for RS determination, as they have relatively low boiling points and are thermally stable. Different aspects of the GC method, such as injection systems, columns, and/or detectors, must be taken into account when developing it. Analyte retention times and detection limits can be reduced using the right system [5]. The headspace analysis extracts volatile and semi-volatile components [6]. A single sample of gas is collected and heated in a sealed vial before being delivered to the GC in a static headspace. Once the gas and liquid have equilibrated, the gas sample is obtained. This approach is the optimum choice when the pharmaceutical samples are soluble in solvents such as water, DMSO, dimethylformamide, dimethylacetamide, dimethyl isosorbide, or benzyl alcohol [7]. Separation is accomplished using capillary and wide-bore columns are used. The most often used stationary phases are polysiloxanes and polyethylene glycols [8]. When the analytes present in the sample are known or suspected, the flame ionization detector (FID) is indicated for GS- RS analysis. Due to its low detection limits, large linear dynamic range, and overall reliability and utility, FID has become the most widely employed detector in GC [9].

In general, static headspace GC analysis with FID detection is the most commonly used method for RS determination in pharmaceuticals. From the scheme of synthesis [10], residual solvents - ethanol, acetone, methanol, acetonitrile, and IPA were used in the synthesis of the palonosetron. The presence of this RS should be validated and quantified for ensuring the safety and efficacy of the drug. The present study created a unique HS-GC approach for the validation and quantification of RS in palonosetron API.

\section{MATERIALS AND METHODS}

Materials

Ethanol and acetone were obtained from Qualigens, Mumbai; methanol, acetonitrile, IPA, and DMSO were obtained from Sigma Aldrich, 
Table 1: Concentration limits and boiling points for the RS present in Palonosetron

\begin{tabular}{lllll}
\hline S. No. & Solvent & PDE (mg/day) & $\begin{array}{l}\text { Concentration } \\
\text { limit }(\mathbf{p p m})\end{array}$ & $\begin{array}{l}\text { Boiling } \\
\text { point }\left({ }^{\circ} \mathbf{C}\right)\end{array}$ \\
\hline 1 & Ethanol & $<50$ & 5000 & 78 \\
2 & Acetone & $<50$ & 5000 & 56 \\
3 & Methanol & 30 & 3000 & 65 \\
4 & Acetonitrile & 4.1 & 410 & 82 \\
5 & IPA & $<50$ & 5000 & 83 \\
\hline
\end{tabular}

*PDE is permitted daily exposure of the RS in $\mathrm{mg}$ /day as mentioned in USP

General Chapter $<467>$ Residual Solvents and ppm is parts per million

Bengaluru. Palonosetron was a gift sample procured from Chandra labs, Hyderabad.

\section{Instrument details}

The study used Agilent infinity 7697A Head Space Gas Chromatography system equipped with a flame ionization detector and Open labs EZ chrome, as well as Mettler Toledo precision balance for weighing.

\section{Method development}

The selection of an appropriate GC system which includes a column, injection system, and detector, is a very crucial step in method development which will result in shorter retention times [5]

\section{Selection of column}

In order for the separation process to work, the stationary phase (SP) and the various chemical and physical properties of the injected sample must be in interaction [11]. In order to properly understand the compounds under investigation, chemistry must be considered [12]. This difference in analytephase interactions is responsible for the wide range of capillary column phases. Consequently, in Column I.D., efficiency and sample capacity can be balanced [13]. As the sample capacity increases, the efficiency of column I.D. decreases. Therefore, lower I.D. indicates higher efficiency. Coming to the next factor, film thickness; decreasing the thickness, a resolution is better but increased signal-to-noise is observed, and increasing the thickness will reduce the resolution by increasing column bleed. Considering all the parameters, film thickness should be selected. Mostly $0.25 \mathrm{~mm}$ I.D. columns have 0.25 or $0.50 \mu \mathrm{m}$ film thickness [12]. Finally, column length: $30 \mathrm{~m}$ column provides the best balance of resolution, analysis time, and required column head pressure [14].

\section{Selection of injection system}

The sample injection technique will have a significant impact on the recovery and reproducibility of GC analysis. In most circumstances, the inlet temperature is maintained at $50^{\circ} \mathrm{C}$ above the lowest boiling point component of the sample mixture (Table 1). The autosampler tray is typically packed with sealed vials, and samples are injected one at a time. Operational software controls the injection volume, number of wash cycles, and injection sequence for standards and samples [15].

\section{Selection of detector}

FID is the most commonly used detector in GC for laboratory analysis. It has a wide dynamic range and is highly sensitive to all substances that contain carbon. The advantages of FID are easy to operate, simple, reliable, versatile, and gives no or little signal for common carrier gases or typical contaminants [16].

By considering all the above-mentioned factors, the following chromatographic conditions were optimized for method development of Palonosetron (Tables 2 and 3).

\section{Optimization details}

DB-624 Column $(30 \mathrm{~m} * 0.24 \mathrm{~mm}, 1.8 \mu \mathrm{m})$ was chosen for HS-GC analysis at a headspace equilibrium temperature of $100^{\circ} \mathrm{C}$. A milliliter of standard and sample solutions was injected into an injection port at $230^{\circ} \mathrm{C}$ for an inlet temperature of $200^{\circ} \mathrm{C}$, which was greater than the lowest boiling point component in the sample mixture. With a flow rate
Table 2: Optimized gas chromatographic conditions for palonosetron

\begin{tabular}{ll}
\hline GC parameter & Condition \\
\hline Column & $\mathrm{DB}-624$ Column $(30 \mathrm{~m} * 0.24 \mathrm{~mm}, 1.8 \mu \mathrm{m})$ \\
Inlet temperature & $200^{\circ} \mathrm{C}$ \\
Detector temperature & $230^{\circ} \mathrm{C}$ \\
Initial oven temperature & $40^{\circ} \mathrm{C}$ \\
Final oven temperature & $120^{\circ} \mathrm{C}$ \\
Carrier gas & Nitrogen \\
Flow rate & $10 \mathrm{ml} / \mathrm{min}$ \\
Split ratio & $1: 25$ \\
\hline
\end{tabular}

Table 3: Optimized headspace conditions for palonosetron

\begin{tabular}{ll}
\hline Headspace parameter & Conditions \\
\hline Oven temperature & $100^{\circ} \mathrm{C}$ \\
Transfer line temperature & $110^{\circ} \mathrm{C}$ \\
GC cycle time & $20 \mathrm{~min}$ \\
Loop fill temperature & $120^{\circ} \mathrm{C}$ \\
\hline
\end{tabular}

of $10 \mathrm{ml} / \mathrm{min}$ and a split ratio of $1: 25$, the beginning oven temperature was set at $40^{\circ} \mathrm{C}$, increasing by $10^{\circ} \mathrm{C} / \mathrm{min}$ over a 5 -min hold period until the final oven temperature $120^{\circ} \mathrm{C}$. Nitrogen was used as the carrier gas, and the GC was performed for $20 \mathrm{~min}$.

\section{Preparation of blank, standard, and sample solution}

All these studies were carried out at room temperature. DMSO was selected as a dissolving solvent in the determination of RS in the Palonosetron API.

For blank vail, $1 \mathrm{ml}$ of DMSO was used. A standard stock solution in DMSO was prepared with each of the RS in Palonosetron API (ethanol, acetone, methanol, acetonitrile, and IPA) at a concentration of $2000 \mu \mathrm{g} / \mathrm{ml}$. This is followed by the preparation of a sub-stock solution with a final concentration of $100 \mu \mathrm{g} / \mathrm{ml}$. For the standard vial, $1 \mathrm{ml}$ of the prepared substock standard solution was taken and for the sample vial, approximately $10 \mathrm{mg}$ of sample in $1 \mathrm{ml}$ DMSO as dissolving solvent was taken.

\section{Method validation}

Method validation is conducted by evaluating the following criteria, in accordance with ICH guidelines: specificity, linearity, precision, accuracy, the limit of detection (LOD), limit of quantification (LOQ), ruggedness, and system adaptability [17].

\section{Specificity}

The specificity is determined by injecting blank, standard, and specificity solutions (composite standard solutions of all residual solvents) and by checking out different parameters such as resolution, tailing factor, and theoretical plates for system suitability.

\section{Linearity}

A series of dilutions of the standard solutions between the concentrations of 25 and $150 \mu \mathrm{g} / \mathrm{ml}$ were made. A linear relationship between the concentrations and the responses of the solvents was represented in a calibration curve form and correlation coefficients with regression equations were calculated statistically.

Limit of detection (LOD) and Limit of quantification (LOQ)

Limit of detection refers to the smallest value of the analyte that the detector is capable of detecting and limit of quantification refers to the smallest amount of analyte the detector is capable of quantifying. Both values were calculated statistically using the following formulas:

$$
\begin{aligned}
& \mathrm{LOD}=3.3^{*}(\sigma / \mathrm{S}) \\
& \mathrm{LOQ}=10^{*}(\sigma / \mathrm{S})
\end{aligned}
$$

Where $\sigma$ is standard deviation and $\mathrm{S}$ is a slope. 


\section{Precision}

Six replicate injections of standard solutions of solvents were taken and analyzed for evaluating system precision according to the harmonized method and the chromatograms were obtained.

\section{Ruggedness}

Six replicate injections of standard solutions of solvents were taken and analyzed by a different analyst to test the ruggedness of the developed method.

\section{Robustness}

Solutions were taken in triplicate by varying temperatures - low, control, and high to determine the robustness of the system.

\section{Accuracy}

The accuracy was determined by spiking all the solvents in triplicates at three distinct concentrations: $75 \%, 100 \%$, and $150 \%$ to the quantitation limit.

\section{RESULTS}

The quantitative determination of the residual solvents methanol, ethanol, acetone, acetonitrile, and IPA in palonosetron API has been developed and validated. Optimizing the chromatographic conditions during method development was critical in the development of this method and validated in accordance with ICH guidelines [17]. The obtained results were found to meet the acceptance criteria. This technique has demonstrated excellent linearity, recovery, and repeatability.

\section{Specificity and system suitability}

The system suitability is tested before starting the analysis by injecting the standard solutions of the solvents. From the data, for the parameters - retention times, resolution, theoretical plates, and tailing factor (Table 4), the values were found to be within the accepted limits and hence pass the test. Fig. 1 depicts a chromatogram of the standard solution. All the peaks were well resolved without any interference with solvent or API peaks and hence the method was found to be specific.

\section{Linearity}

To establish a linear relationship between residual solvent concentration and average peak area, a graph of concentration vs average peak area was produced and correlation coefficient, y-intercept, and slope of the regression was determined [18-21]. The linearity acceptance condition, $\gamma^{2}$ should be $>0.99$. Table 5 contains the linearity results.

\section{LOD and LOQ}

Using the above-mentioned statistical formulas, the values for LOD and LOQ were calculated. The acquired values were listed in Table 5.

\section{Precision}

The standard deviation and percentage relative standard deviation (percent RSD) were calculated in this method to determine the system's precision. Acceptance limits for method and system precision should be percent RSD NMT 10\%. The data obtained were represented in mean(SD) values which indicate the reliability of this study. The \%RSD values were found to be 2.51 for acetone, 3.40 for methanol, 3,17 for ethanol, 3.59 for acetonitrile, and 3.69 for IPA. By observing the results in Table 6 it clearly understood that the \%RSD values were within the limits and below 5\%; method and system were said to be precise.

\section{Ruggedness}

Ruggedness is a criterion for determining the constancy of the results when the external factors such as analyst, instrument, and lab are varied. In this developed method, ruggedness has been carried out by different analysts, and the results were found to be satisfactory for which the \%RSD values were below $5 \%$ (Table 7).

\section{Robustness}

It is a statistic that indicates a method's capacity to remain unaffected by deliberate parameter changes. Robustness was
Table 4: Specificity and system suitability parameters

\begin{tabular}{lllll}
\hline Solvent & $\begin{array}{l}\text { Retention } \\
\text { time (min) }\end{array}$ & $\begin{array}{l}\text { Tailing } \\
\text { factor }\end{array}$ & $\begin{array}{l}\text { Theoretical } \\
\text { Plates }\end{array}$ & Resolution \\
\hline Acetone & 2.86 & 1.2 & 5184 & - \\
Methanol & 5.28 & 1.0 & 7744 & 18.46 \\
Ethanol & 7.34 & 1.1 & 8464 & 10.42 \\
Acetonitrile & 9.55 & 1.4 & 9525.8 & 8.46 \\
IPA & 13.00 & 1.0 & 11664 & 17.6 \\
$\begin{array}{l}\text { Acceptance } \\
\text { Criteria (For }\end{array}$ & - & NMT 2 & NLT 5000 & NLT 1.5 \\
information) & & & & \\
\hline *NMT: Not more than, NLT: Notless than & &
\end{tabular}

*NMT: Not more than, NLT: Not less than

Table 5: Linearity, LOD, and LOQ values

\begin{tabular}{lllll}
\hline Solvent & $\begin{array}{l}\text { Linearity } \\
\left(\boldsymbol{\gamma}^{2}\right)\end{array}$ & Slope & LOD $(\boldsymbol{\mu g} / \mathrm{ml})$ & LOQ $(\boldsymbol{\mu g} / \mathbf{m l})$ \\
\hline Acetone & 0.991 & 149.22 & 5.72 & 17.33 \\
Methanol & 0.994 & 222.736 & 7.25 & 21.9 \\
Ethanol & 0.999 & 104.044 & 9.64 & 29.21 \\
Acetonitrile & 0.99 & 1186.96 & 8.10 & 24.55 \\
IPA & 0.997 & 209.832 & 9.77 & 29.60 \\
\hline
\end{tabular}

*Where LOD and LOQ are limits of detection and limit of quantification, respectively measured in $\mu \mathrm{g} / \mathrm{ml} ; \gamma^{2}$ indicates correlation coefficient values.<smiles>O=C1c2cccc3c2[C@H](CCC3)CN1[C@@H]1CN2CCC1CC2</smiles>

Fig. 1: Structure of palonosetron

determined in this method by varying the temperature of the oven (Table 8).

Accuracy

Accuracy is determined by calculating the percentage recovery at three different levels in triplicates by the formula:

$\%$ Recovery $=\left[\left(\mathrm{A}_{\mathrm{sp}}-\mathrm{A}_{\mathrm{s}}\right) / \mathrm{A}_{\mathrm{std}}\right] * 100$

Where $\mathrm{A}_{\mathrm{sp}}$ denotes the solvent area in a spiked sample, $\mathrm{A}_{\mathrm{s}}$ denotes the solvent area in sample and $A_{\text {std }}$ denotes the solvent area in standard solution.

The acceptance limit of \%recovery for accuracy is $80-120 \%$. The values for the accuracy data were given in Table 9 and all of them were found to be within the prescribed limits (Table 10).

\section{DISCUSSION}

From the literature, its understood that very few analytical methods have been reported for palonosetron [18-20] which includes the methods viz., UV, single-dose, and fixed-dose method development and validation of palonosetron using HPLC, whereas the HS-GC method has not been reported.

The developed method has passed the system suitability (Table 4) and was found to be specific as there is no interference at the retention times of the targeted residual solution from each other and solvent peaks or unknown peaks (Fig. 2). The retention times of acetone, methanol, ethanol, acetonitrile, and IPA were found to be 2.860, 5.286, 7.346, 9.563, 13.007 min respectively. 
Table 6: Results for precision

\begin{tabular}{|c|c|c|c|c|c|c|c|c|c|c|}
\hline \multirow{2}{*}{$\begin{array}{l}\text { Solvent } \\
\text { Parameters }\end{array}$} & \multicolumn{2}{|l|}{ Acetone } & \multicolumn{2}{|l|}{ Methanol } & \multicolumn{2}{|l|}{ Ethanol } & \multicolumn{2}{|l|}{ Acetonitrile } & \multicolumn{2}{|l|}{ IPA } \\
\hline & Area & RT & Area & RT & Area & RT & Area & RT & Area & RT \\
\hline Standard 1 & 10056.6 & 2.86 & 14245.7 & 5.27 & 9310.8 & 7.34 & 80974.6 & 9.53 & 26059.0 & 13.0 \\
\hline Standard 3 & 10175.4 & 2.86 & 14000.3 & 5.28 & 9585.0 & 7.34 & 78787.7 & 9.55 & 16202.3 & 13.0 \\
\hline Standard 4 & 10806.8 & 2.86 & 15354.7 & 5.28 & 10141.8 & 7.34 & 86837.4 & 9.55 & 17788.2 & 13.0 \\
\hline Standard 5 & 10250.9 & 2.85 & 14096.0 & 5.28 & 9653.4 & 7.34 & 79121.7 & 9.55 & 16383.9 & 13.0 \\
\hline Standard 6 & 10626.8 & 2.86 & 14947.9 & 5.28 & 9963.8 & 7.34 & 84120.6 & 9.55 & 17408.9 & 13.0 \\
\hline Mean (SD); $\mathrm{n}=6$ & 10311 (258.7) & - & $14396(490.0)$ & - & 9601.1 (303.9) & - & 81242 (2914.3) & - & $16855(621.2)$ & - \\
\hline$\%$ RSD & 2.51 & - & 3.40 & - & 3.17 & - & 3.59 & - & 3.69 & - \\
\hline
\end{tabular}

*Where RT is retention time in mins, SD is standard deviation, \%RSD is percentage relative standard deviation and n is number of observations.

Table 7: Results for ruggedness

\begin{tabular}{|c|c|c|c|c|c|c|c|c|c|c|}
\hline \multirow{2}{*}{$\begin{array}{l}\text { Solvent } \\
\text { Parameters }\end{array}$} & \multicolumn{2}{|l|}{ Acetone } & \multicolumn{2}{|l|}{ Methanol } & \multicolumn{2}{|l|}{ Ethanol } & \multicolumn{2}{|l|}{ Acetonitrile } & \multicolumn{2}{|l|}{ IPA } \\
\hline & Area & RT & Area & RT & Area & RT & Area & RT & Area & RT \\
\hline Standard 1 & 10068.7 & 2.86 & 14246.1 & 5.29 & 9301.4 & 7.35 & 80983.9 & 9.56 & 16261.3 & 13.0 \\
\hline Standard 3 & 10183.5 & 2.86 & 14001.2 & 5.28 & 9582.2 & 7.34 & 78775.0 & 9.55 & 16205 & 13.0 \\
\hline Standard 4 & 10817.1 & 2.86 & 15356.6 & 5.28 & 10143.2 & 7.34 & 86817.0 & 9.55 & 17786.4 & 13.0 \\
\hline Standard 5 & 10262.7 & 2.85 & 14099.3 & 5.28 & 9662.5 & 7.33 & 79111.5 & 9.55 & 16382.4 & 13.0 \\
\hline Standard 6 & 10639.7 & 2.87 & 14950.9 & 5.28 & 9961.0 & 7.34 & 84108.1 & 9.55 & 17408.0 & 13.0 \\
\hline Mean (SD); $n=6$ & 10375 (263.9) & - & $14488.4(493.3)$ & - & 9659.6 (311.8) & - & 81714.9 (2907) & - & 16746.7 (615.9) & - \\
\hline$\%$ RSD & 2.54 & - & 3.41 & - & 3.23 & - & 3.56 & - & 3.68 & - \\
\hline
\end{tabular}

*Where RT is Retention Time in mins., SD is standard deviation, \%RSD is relative standard deviation and $\mathrm{n}$ is number of observations.

Table 8: Results for robustness

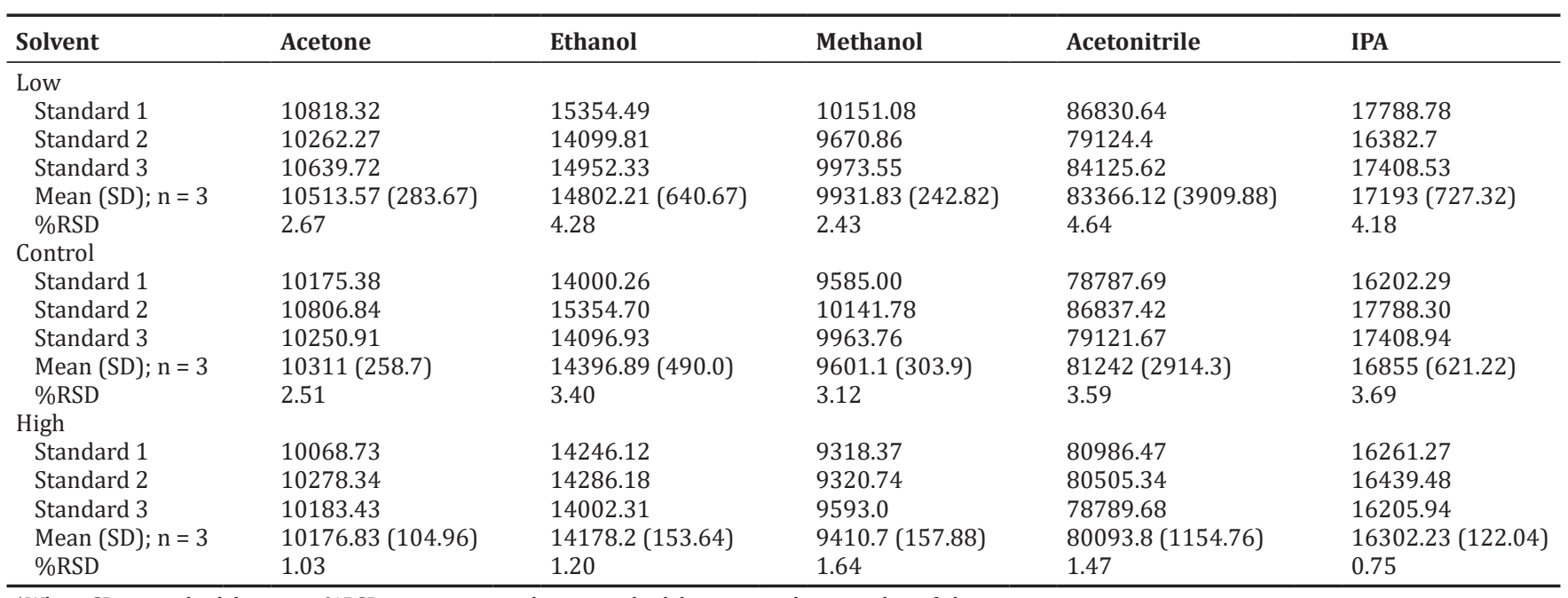

*Where SD is standard deviation, \%RSD is percentage relative standard deviation and $\mathrm{n}$ is number of observations.

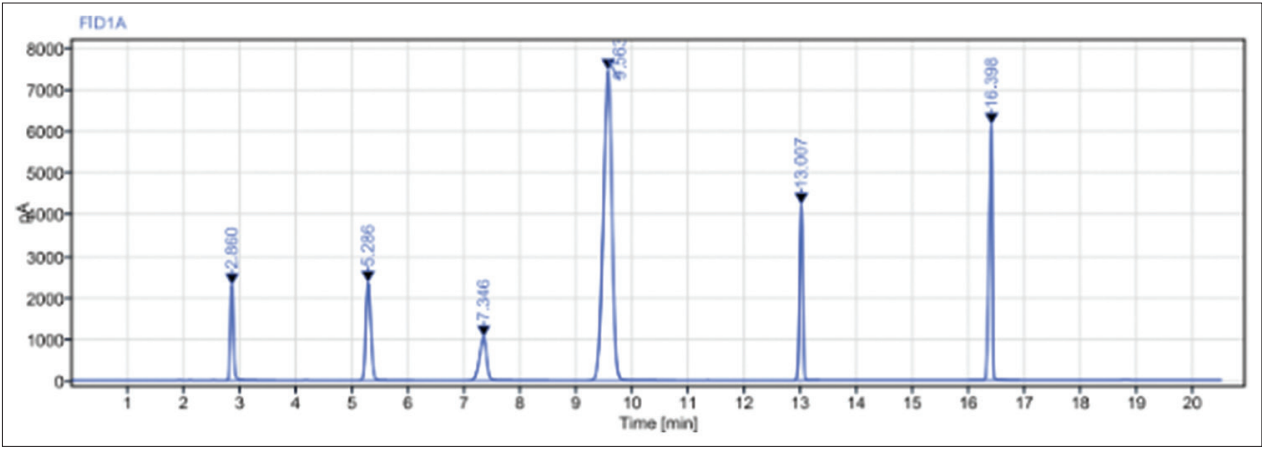

Fig. 2: A typical chromatogram of standard solution 


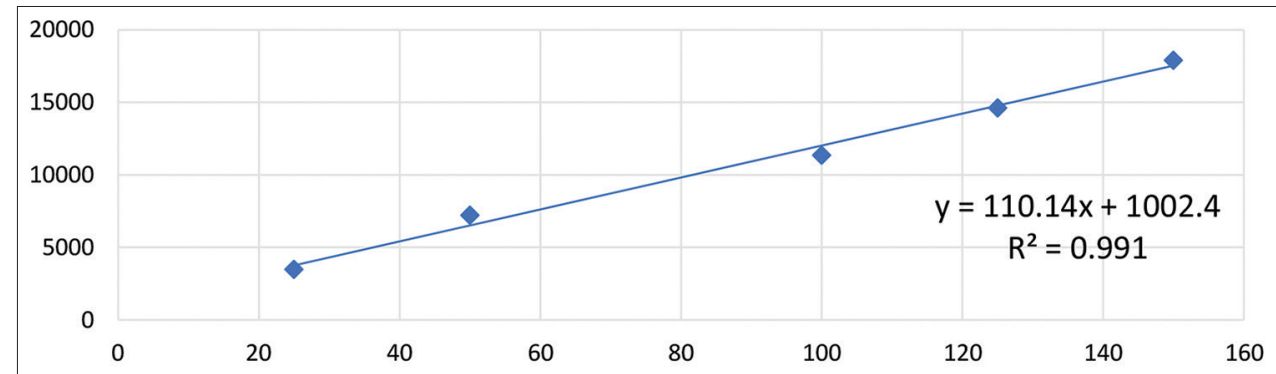

Fig. 3: Linearity graph for acetone

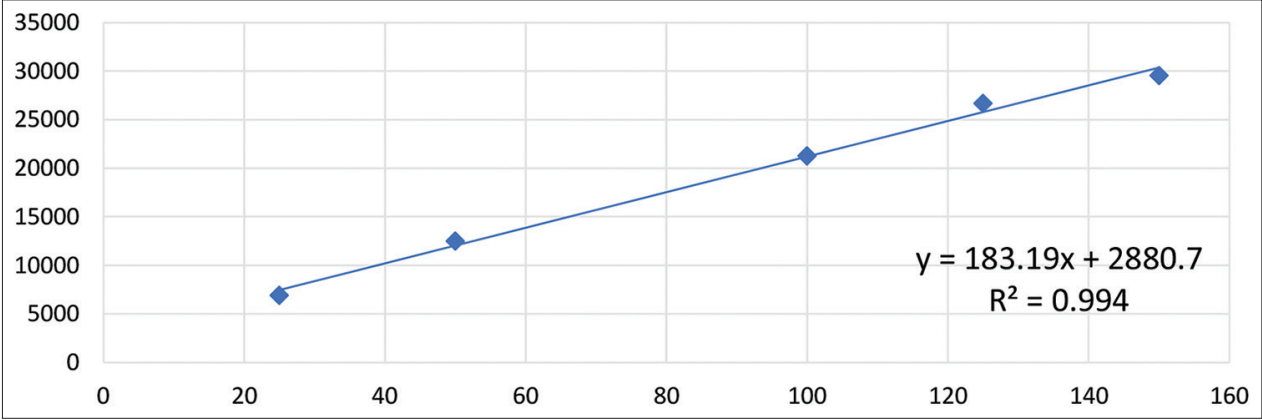

Fig. 4: Linearity graph for methanol

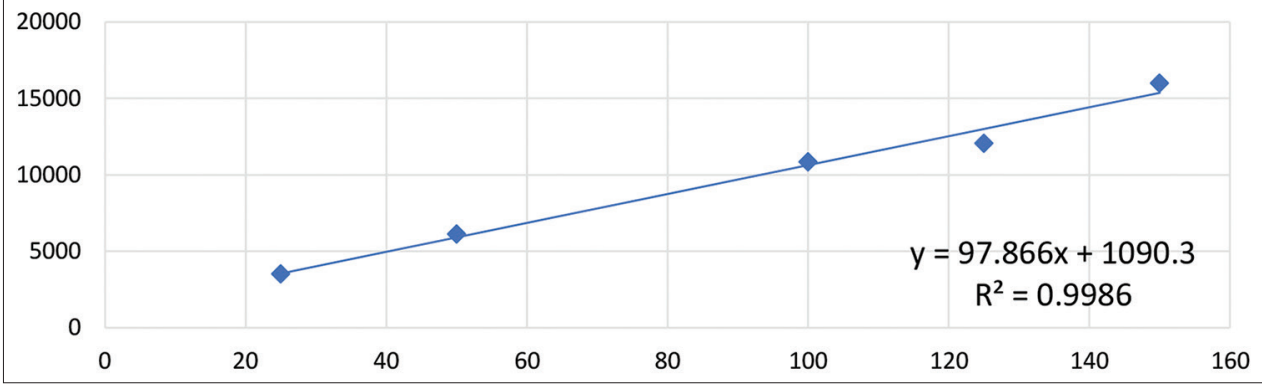

Fig. 5: Linearity graph for ethanol

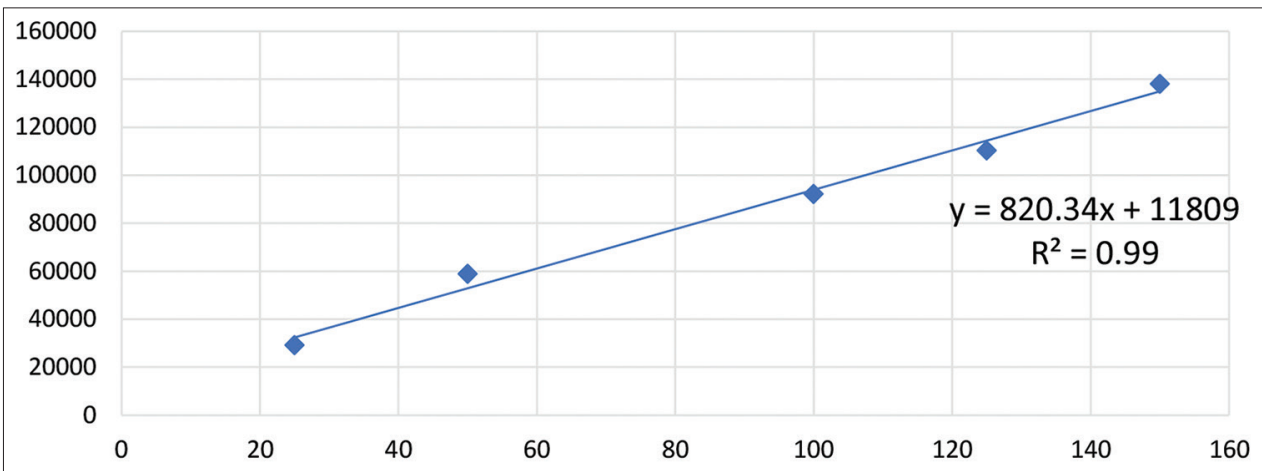

Fig. 6: Linearity graph for acetonitrile

The linearity was evaluated within the concentration range 25-150 $\mu \mathrm{g} /$ $\mathrm{ml}$ for the residual solvents- acetone, methanol, ethanol, acetonitrile, and IPA, for which $\gamma^{2}$ values were found to be $>0.99$ (Figs. 3-7 and Table 5), hence, the method was linear. LOD values were found to be $5.72 \mu \mathrm{g} / \mathrm{ml}$ for acetone, $7.25 \mu \mathrm{g} / \mathrm{ml}$ for methanol, $9.64 \mu \mathrm{g} / \mathrm{ml}$ for ethanol, $8.10 \mu \mathrm{g} / \mathrm{ml}$ for acetonitrile, and $9.77 \mu \mathrm{g} / \mathrm{ml}$ for IPA. LOQ values were found to be $17.33 \mu \mathrm{g} / \mathrm{ml}$ for acetone, $21.9 \mu \mathrm{g} / \mathrm{ml}$ for methanol, $29.21 \mu \mathrm{g} / \mathrm{ml}$ for ethanol, $24.55 \mu \mathrm{g} / \mathrm{ml}$ for acetonitrile, and $29.60 \mu \mathrm{g} /$ $\mathrm{ml}$ for IPA. These values were found to be satisfactory(Table 5). \%RSD values for precision, ruggedness, and robustness were found to be NMT
$10 \%$ which signifies the reliability and reproducibility of the study (Tables 6-8). The values obtained for percentage recoveries of the solvents prove the accuracy of this method (Table 9). Excellent results were achieved with a faster run time of $20 \mathrm{~min}$.

\section{CONCLUSION}

For the determination of residual solvents in palonosetron API, a simple HS-GC method has been developed using flame ionization detection and quantitatively proven to be both accurate and precise. 


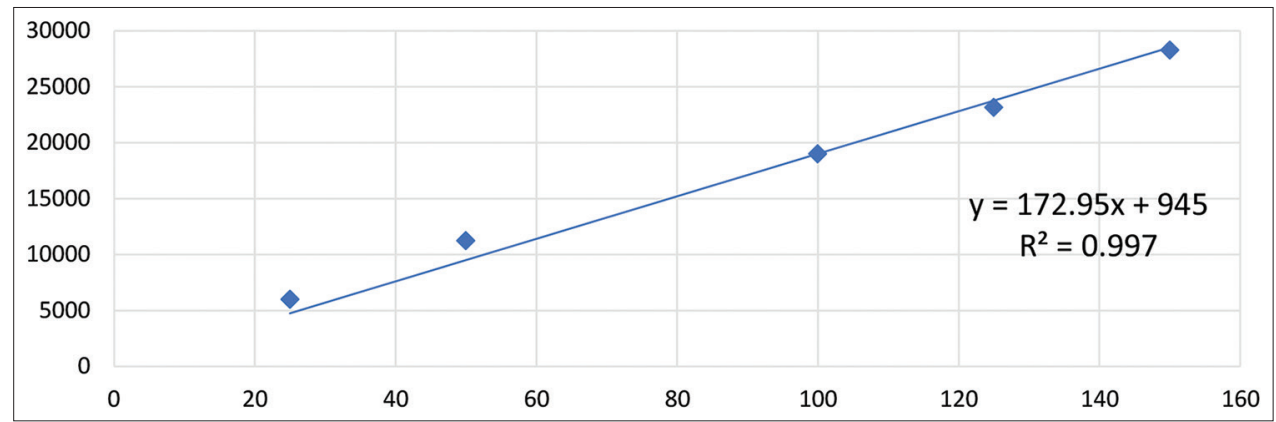

Fig. 7: Linearity graph for IPA

Table 9: Results for recovery studies

\begin{tabular}{llllll}
\hline $\begin{array}{l}\text { Spiking level } \\
\text { (\% of QL) }\end{array}$ & Acetone & Methanol & Ethanol & Acetonitrile & IPA \\
\hline $50 \%-\mathrm{R}-1$ & 84.75 & 118.31 & 91.24 & 87.68 & 87.57 \\
R-2 & 85.23 & 116.20 & 94.13 & 88.56 & 89.43 \\
R-3 & 88.61 & 115.15 & 92.60 & 88.13 & 86.43 \\
$100 \%-\mathrm{R}-1$ & 100.70 & 98.26 & 104.06 & 96.35 & 99.72 \\
R-2 & 102.87 & 99.01 & 105.32 & 98.87 & 98.63 \\
R-3 & 102.65 & 98.40 & 103.11 & 99.54 & 98.04 \\
$150 \%-\mathrm{R}-1$ & 98.47 & 110.59 & 95.12 & 95.40 & 94.44 \\
R-2 & 99.14 & 113.76 & 96.71 & 96.18 & 95.64 \\
R-3 & 99.01 & 111.13 & 96.54 & 96.65 & 96.32 \\
\hline
\end{tabular}

${ }^{*} \mathrm{QL}$ is the quantification limit and $\mathrm{R}$ is recovery percentage.

Table 10: Summary of validation parameters

\begin{tabular}{|c|c|c|}
\hline Parameter & Result & Acceptance Criteria \\
\hline Specificity & $\begin{array}{l}\text { No interference of } \\
\text { solvent peaks w.r.t. } \\
\text { diluent or API peaks. }\end{array}$ & Good peak resolution \\
\hline System Suitability & $\begin{array}{l}\text { 1. Tailing factor - } \\
\text { 1.0-1.4 } \\
\text { 2. Theoretical plates - } \\
5184-11686 \\
\text { 3. Resolution- >1.5 }\end{array}$ & $\begin{array}{l}\text { NMT } 2 \\
\text { NLT } 5000 \\
\text { NLT } 1.5\end{array}$ \\
\hline Linearity & $\gamma^{2}-0.990-0.997$ & $\gamma^{2}>0.99$ \\
\hline LOD & $5.72-9.77 \mu \mathrm{g} / \mathrm{ml}$ & Satisfactory \\
\hline LOQ & $17.33-29.60 \mu \mathrm{g} / \mathrm{ml}$ & Satisfactory \\
\hline Precision $(n=6)$ & \%RSD - 2.51-3.69 & NMT $10 \%$ \\
\hline Ruggedness $(n=6)$ & \%RSD - 2.54-3.68 & NMT $10 \%$ \\
\hline Robustness $(n=3)$ & \%RSD - 0.75-4.64 & NMT $10 \%$ \\
\hline Accuracy & $\begin{array}{l}\text { R1 - 84.75-118.31\% } \\
\text { R2 - 96.35-105.32\% } \\
\text { R-3 - 94.44-113.76\% }\end{array}$ & R - 80-120\% \\
\hline
\end{tabular}

*w.r.t: With respect to; API: Active pharmaceutical ingredient; NMT: Not more than; NLT: Not less than; $\gamma^{2}$ : Correlation coefficient; LOD: Limit of detection; LOQ: Limit of quantification; \%RSD: Percentage relative standard deviation; R: Recovery percentage; R1, R2 and R3 are recovery percentages at 50\%, 100\% and $150 \%$ respectively.

In universities and small-scale companies, this method can be used for routine testing.

\section{ACKNOWLEDGEMENT}

Our sincere gratitude to the Centre for Scientific and Industrial Research(CSIR), New Delhi and University College of Technology, Osmania University, Hyderabad.

\section{AUTHORS CONTRIBUTION}

Research work, analysis of data, preparation, and drafting of a manuscript was done by G. Sunny Grace; and thorough review and revision of manuscript was done by G. Vijaya Lakshmi.

\section{CONFLICT OF INTEREST}

None.

\section{AUTHORS FUNDING}

Financial assistance was provided by the Centre for Scientific and Industrial Research(CSIR), New Delhi.

\section{REFERENCES}

1. Aapro MS. Palonosetron as an antiemetic and anti-nausea agent in oncology. Ther Clin Risk Manag 2007;3:1009-20.

2. Hesketh P, Rossi G, Rizzi G, Palmas M, Alyasova A, Bondarenko I, Lisyanskaya A, et al. Efficacy and safety of NEPA, an oral combination of netupitant and palonosetron, for prevention of chemotherapy-induced nausea and vomiting following highly emetogenic chemotherapy: A randomized dose-ranging pivotal study. Ann Oncol 2014;25:1340-6.

3. Grodowska K, Parczewski A. Analytical methods for residual solvents determination in pharmaceutical products. Acta Pol Pharm 2010;67:1326.

4. Bauer M, Barthelemy C. Handbook of Solvents. Vol. 1. Canada: ChemTec Publishing; 2001. p. 1129.

5. Hymer C. Residual solvent testing: A review of gas-chromatographic and alternative techniques. Pharm Res 2003;20:337-44.

6. Anerao A, Patil B, Pradhan N. Determination of residual dimethyl sulfate in methoxsalen drug substance by pre-column derivatization with static headspace gas chromatography. Int J Pharm Pharm Sci 2018;10:84-9.

7. Wenzyl T, Lankmayr EP. Comparative studies of static and dynamic headspace extraction of saturated short chain aldehydes from cellulosebased packaging materials. Anal Bioanal Chem 2002;372:649-53.

8. Nazarenko AY. Liquid phase headspace microextraction into a single drop. Am Lab 2004;36:30-5.

9. Westmorland DG, Rhodes GR. Analytical techniques for trace organic compounds-II. Detectors for gas chromatography. Pure Appl Chem 1989;61:1147-60.

10. Ravi JR, Reddy MP, Satya BR, Chowdary NV. An Improved Process for the Preparation of Pure Palonosetron Hydrochloride, WIPO (PCT), WO2009/010987A1; 2009.

11. Sigma-Aldrich Supelco: GC Column Selection Guide-Achieve Optimal Method Performance, US No. 800-325-3010; 2013. p. 1-6.

12. McNair H, Miller J. Basic Gas Chromatography. Vol. 471. New York, United States: Wiley; 1997. p. 17261-8.

13. Grant D. Capillary Gas Chromatography. Vol. 471. New York, United States: Wiley; 1996. p. 95371-6.

14. Rood D. A Practical Guide to the Care, Maintenance, and Troubleshooting of Capillary Gas Chromatographic Systems. Vol. 3. Missouri, United States: Huttig; 1991. p. 1898-904.

15. Lab-Training: Sample Injection Practices in Gas Chromatography; 2015.

16. Hage DS. Chromatography: Principles and Applications of Clinical Mass Spectrometry. Vol. 1. Amsterdam, Netherlands: Elsevier; 2018. p. 1-32.

17. International Conference on Harmonization, Impurities: Guidelines for Residual SOLVENTS. ICH Harmonized Tripartite Guideline; 1997.

18. Panigrahy UP, Reddy AS. A novel validated RP-HPLC-DAD method for simultaneous estimation of netupitant and palonosetron in bulk and pharmaceutical dosage form with forced degradation studies. Int $\mathrm{J}$ ChemTech Res 2015;8:317-37.

19. Kumar GV, Sravanthi B, Aparna NG. Development and validation 
of RP-HPLC method for simultaneous estimation of netupitant and palonosetron in pharmaceutical dosage form. Indo Am J Pharm Sci 2018;5:16746-55.

20. Singh NP, Goud, VM, Sharma JV, Sirisha P, Devi C. A review on analytical methods for the determination of palonosetron in pharmaceutical formulation. Int J Pharm Sci Rev Res 2020;60:91-3.

21. Nalini CN, Ramachandran S, Uma G, Suresh P. Gas chromatography method development and method validation of residual solvent (isopropyl alcohol) in magnesium valproate. Int $\mathrm{J}$ Pharm Pharm Sci 2012;4:627-31. 